\title{
RISK ANALYSIS OF ALTERNATIVES TO N-1 RESERVES IN A NETWORK WITH LARGE AMOUNTS OF WIND POWER
}

\author{
Math BOLLEN \\ STRI - Sweden \\ math.bollen@stri.se
}

\author{
Yu CHEN \\ STRI - Sweden \\ yu.chen@stri.se
}

\author{
Nicholas ETHERDEN \\ STRI - Sweden \\ Nicholas.etherden@stri.se
}

\begin{abstract}
This paper analyses the risks associated with applying smart grid technologies to allow more wind power production than is possible with classical network planning. The smart technologies studied include local supervision of network loading, special protection schemes, grid-wide supervision and dynamic rating of overhead lines. The methods have been studied through simulations on an existing 130-kV grid. It is shown that alternatives to the $N-1$ criterion are possible. Such alternatives allow for much more wind power to be connected, without endangering the reliability of supply for other network users.
\end{abstract}

\section{INTRODUCTION}

In recent years, many new technologies, methods, etc. have been proposed that allow for a better and/or more costeffective design and operation of the power system, e.g. [1]. An important driving force of the development of such "smart grids" is the need to integrate more wind power. Many methods for this are under study or in development. In this paper, some of the methods discussed in [1] and [2] are developed further. The specific application studied here is the integration of wind power in a meshed subtransmission network. For more details of the study and its results, the reader is referred to [3].

\section{THE ALTERNATIVE SOLUTIONS}

\section{The $\mathbf{N}-1$ criterion}

The N-1 operational criterion ensures a high reliability of transmission and subtransmission networks. It does however set a severe limit to the amount of wind power that can be connected because of the need to have spare capacity available in the network. If the reserve could be made available in another way, e.g. by reducing consumption or production, this may result in a much higher ability of the network to accept wind power. In the forthcoming sections, four alternatives are discussed that allow for the network to be used more effectively without endangering the reliability of the supply.

\section{Local supervision}

A supervisory system in the local substation reduces the wind power production whenever the net injection into the network exceeds a pre-defined limit, see Fig. 1.

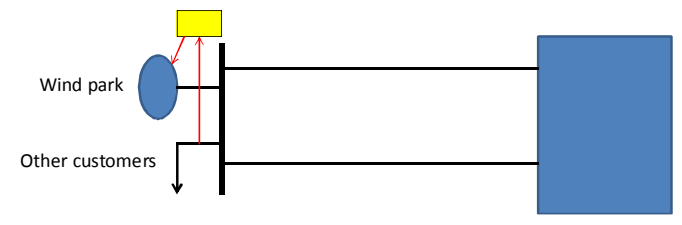

Fig. 1. Solution 1: local supervision

\section{Special protection system}

In the second solution, changes in the network impact the maximum production from wind power. Whenever one of the four breakers in Fig. 2 opens, an intertrip signal is generated that removes all or some of the wind power. Such intertrip schemes are not uncommon in the transmission and subtransmission grids of many countries and have been present since long before wind-power became an issue at these voltage levels. In a modern variant of the scheme, a curtailment signal is generated instead of a trip signal.

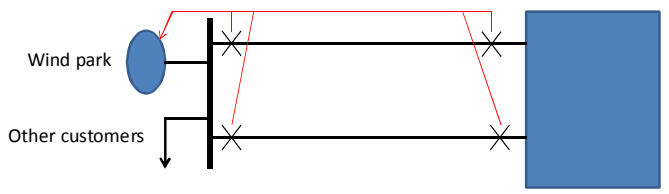

Fig. 2. Solution 2: special protection system

\section{Global supervision}

In this solution, the previous two solutions are combined, as shown in Fig. 3. The signal generated by the tripping of one of the indicated breakers is no longer directly sent to the wind farm but to the local supervisory system.

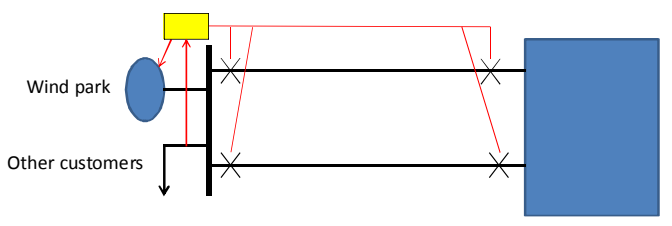

Fig. 3. Solution 3: global supervisory system

\section{Dynamic line rating}

With dynamic line rating, Fig. 4 , the ampacity of the line is calculated for example every hour. There are different methods available for this, all of which are still under development. A direct method would be based on measuring the conductor temperature and/or tension at several locations along the line and comparing this with design values. Indirectly, the (dynamic) ampacity might be calculated based on measurements and/or predictions of temperature, wind speed, etc along the line. 


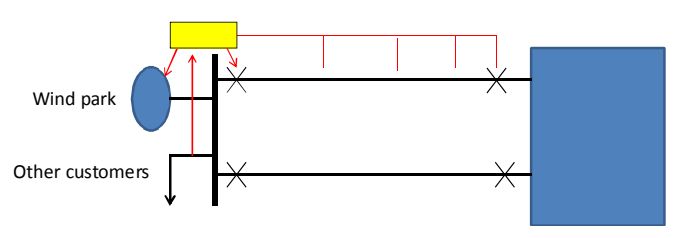

Fig. 4. Solution 4: dynamic line rating

\section{THE CASE STUDY}

The four alternatives described in the previous section, and the base case in which the $\mathrm{N}-1$ criterion is used, have been studied for the network shown in Fig. 5. The network is based on an existing $130-\mathrm{kV}$ network in Sweden. Actual hourly consumption has been used for all busses, over a two year period. Actual hourly production data for a 34-MW wind park with bus 7 has been used, over the same two-year period. This production data has been scaled to the installed capacity values in the study. Hourly weather data has been obtained from a location about $50 \mathrm{~km}$ from the wind park, again over the same two-year period.

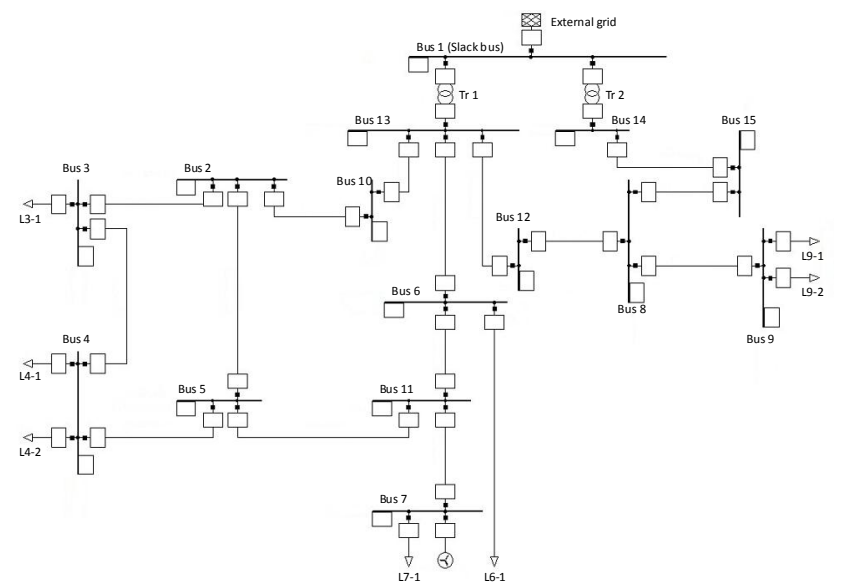

Fig. 5. Network used to quantify the differences between the different solutions, based on an existing 130-kV network in Sweden.

For every hour and every value of the installed capacity of wind power, a dc load flow has been performed to obtain the currents through all the lines. These currents are compared with the (static or dynamic) line ratings. The actual conductor configuration has been used to calculate the line rating.

\section{QUANTIFYING THE RISKS}

\section{Network and park hosting capacity}

A difference has been made between the "network hosting capacity" (NHC) and the "park hosting capacity" (PHC), as shown in Fig. 6. The NHC is the maximum net amount that can be securely injected into the network (i.e. without endangering the reliability or operational security), whereas the PHC is the maximum amount that can be securely produced by the park. The distinction between network hosting capacity and park hosting capacity allows for a separate treatment of the limitations set by the network and the limitations due to the local variations in production and consumption.

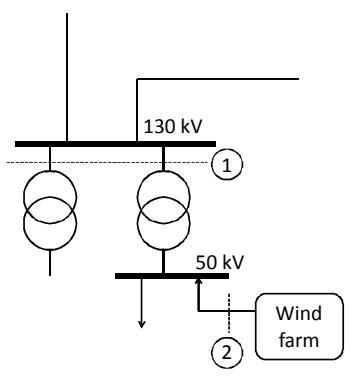

Fig. 6. Network hosting capacity (1) and park hosting capacity (2).

The difference between PHC and NHC, the PHC being the higher one, is due to the local consumption. Three cases are considered:

1. The lowest PHC is obtained when maximum production is assumed together with zero consumption. In that case $\mathrm{NHC}$ and PHC are the same and the probability of overload in the grid is very small.

2.

A higher PHC is obtained when maximum production is assumed together with known minimum consumption. The PHC is in that case equal to the NHC plus the minimum consumption. Grid overload might occur in this case when the consumption is lower than the expected minimum at the same time that the production is high. The probability of this happening depends mainly on the method used to estimate the minimum consumption. When hourly data from one or more years is used, this probability is perceived low, unless there are clear changes in type of consumption.

3. An even higher value of the PHC is obtained when hourly values of production and consumption are used. The increased in hosting capacity obtained by true timeseries data depends on the correlation between production and consumption. The limitation of this method is that data will only be available for a limited number of years and in many cases production data has to be estimated (e.g. from past weather data) as no production was present at or near the location of the new installation. It was concluded from the studies that use of actual wind production data instead of installed capacity (or maximum wind production) raises the PHC by 20 to $30 \mathrm{MW}(15$ to $25 \%)$. It is further found that the difference between the two years used in this study is small. It is thus possible to obtain a suitable value for the PHC from the hourly data over a small number of years. The risk here is that large changes in consumption pattern occur; a reduction of consumption (e.g. due to energy efficiency measures) will result in less wind power being able to be connected. When no curtailment is possible (which is the assumption for the base case), such a reduction in consumption would require additional investments in the grid to be carried by the network operator.

A general observation is that a higher hosting capacity will in general result in higher risks for the network operator (risk of line overloading; risk of future investments) and for other network users (risk of supply interruptions due to line overloading, risk of increased use of system tariffs to cover future investments). A higher hosting capacity has advantages for the wind park owner (more installed capacity for the same connection), for society as a whole (more energy from 
renewable sources) and for the network owner (if their income is determined by transfer fees and not purely by capital and operation cost).

\section{Special protection systems}

The maximum-permissible net injection (the NHC) has been calculated for nine busses (Fig. 7); for the case with all lines in operation (labelled "meshed" in Fig. 7) and for 13 cases with one line out of operation.

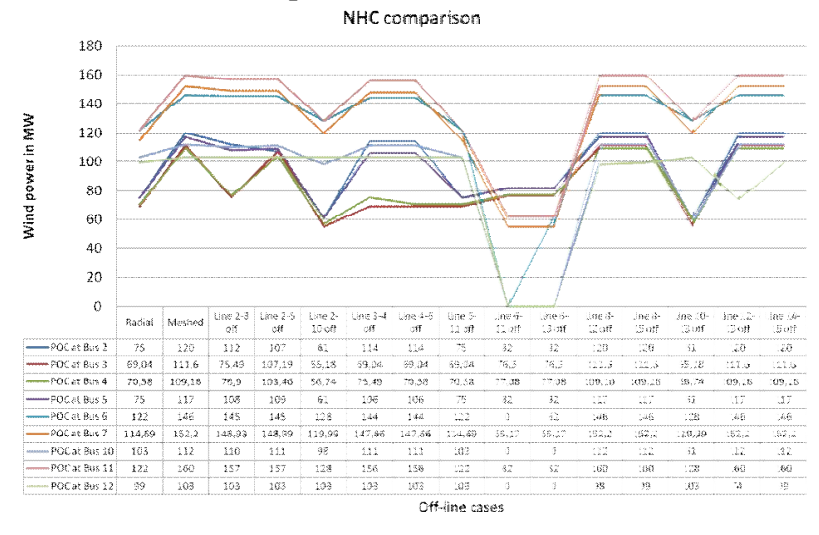

Fig. 7. Network hosting capacity for different operational states of the network.

The hosting capacity for the base case (N-1 criterion) is the lowest value for any of the line outages. The PHC for the base case ("without SPS") and for solution two ("with SPS") are presented in Table 1. The use of the special protection system allows for much more wind power to be connected. The PHC has been obtained as the NHC plus minimum consumption.

Table 1 Increase in hosting capacity using a special-protection sy
\begin{tabular}{c|c|c|}
\hline \multirow{2}{*}{ POC } & \multicolumn{2}{|c|}{ Hosting capacity (PHC) } \\
\hline & Without SPS & With SPS \\
\hline 2 & $61 \mathrm{MW}$ & $120 \mathrm{MW}$ \\
\hline 3 & $61 \mathrm{MW}$ & $123 \mathrm{MW}$ \\
\hline 4 & $61 \mathrm{MW}$ & $113 \mathrm{MW}$ \\
\hline 5 & $61 \mathrm{MW}$ & $117 \mathrm{MW}$ \\
\hline 6 & $*$ & $146 \mathrm{MW}$ \\
\hline 7 & $62 \mathrm{MW}$ & $160 \mathrm{MW}$ \\
\hline 10 & $*$ & $112 \mathrm{MW}$ \\
\hline 11 & $62 \mathrm{MW}$ & $160 \mathrm{MW}$ \\
\hline 12 & $*$ & $103 \mathrm{MW}$ \\
\hline
\end{tabular}

* The loss of certain lines will cause the network to be overloaded due to consumption. Although a wind power installation does not necessarily deteriorate the situation, a PHC cannot be defined in these cases.

Reduction of the production is needed only when one of the lines is not available. Using realistic values for unavailability for this kind of lines, this is during $0.04 \%$ of the time. When the production is reduced to zero (the worst case) the loss of production will be only $0.04 \%$, assuming there is no correlation between line outages and wind-power production. Even if this amount is low, a permanent outage of the "wrong" line over several months may be catastrophic for the economy of a small wind farm owner. Rather than investing in grid redundancy for such a low probability event it may be more economical to purchase insurance against this risk.

When it takes a certain time to restore the production, the behaviour during temporary outages becomes of importance. With intertrip schemes, the opening of a breaker will result in automatic tripping of the park. Reconnection of the park will typically be manual and thus require a certain amount of time. The unavailability of the park due to temporary outages might easily be more than the unavailability due to permanent outages.

To get an impression of the order of magnitude, consider that there are 10 outages per year that result in tripping of all wind-power production. Assume further that it takes 2 hours to restart production. Together with the before-mentioned 4 hours due to permanent outages, the park is disconnected during 24 hours per year or $0.3 \%$ of time. Even in this extreme case the loss of production will be only $0.3 \%$.

Even though this $0.3 \%$ is a small percentage (the uncertainty in the prediction of the number of production hours per year is bigger), an economic assessment should be done. Consider for this a $120 \mathrm{MW}$ wind park with a production equivalent to 3000 hours/year. Assume that the price paid for the energy from the park (green certificates plus day-ahead spot price) is $700 \mathrm{SEK} / \mathrm{MWh}$. The annual income of the park would be 252 million SEK/year, and $0.3 \%$ loss of production would correspond to a loss of income equal to $756000 \mathrm{SEK} /$ year. The gain in production would in most cases not cover more than one or two kilometres of line. Note that we have used an upper limit for the loss of production; a value of $0.1 \%$ or less appears more realistic.

\section{Curtailment}

With solutions 1, 3 and 4, there is no longer a hard limit to the amount of wind power that can be installed. The curtailment algorithm ensures that the production never reaches a value that is dangerous for the network.

A higher installed capacity will no longer result in an increased probability of overload, but in an increased amount of curtailed energy. The risk is thus moved from the network operator and other network users to the wind-park owner. The amount of curtailed energy as a function of the installed capacity, for a park connected to bus 7, is shown in Fig. 8. According to the figure, curtailment has negligible impact on the delivered energy up to about $160 \mathrm{MW}$ for solution 1 and $220 \mathrm{MW}$ for solution 2. For increasing installed capacity, curtailment is activated more often and the curtailed energy increases. The income from sales of the energy becomes less. Above a certain installed capacity, it will no longer be economically attractive to add more wind power.

The figure also shows the hosting capacity for the different solutions, where the actual correlation between production and consumption has been used (case 3 below Fig. 6). For solution 1, 3 and 4 this is the installed capacity above which curtailment was activated at least one hour during the two years for which data had been used. 


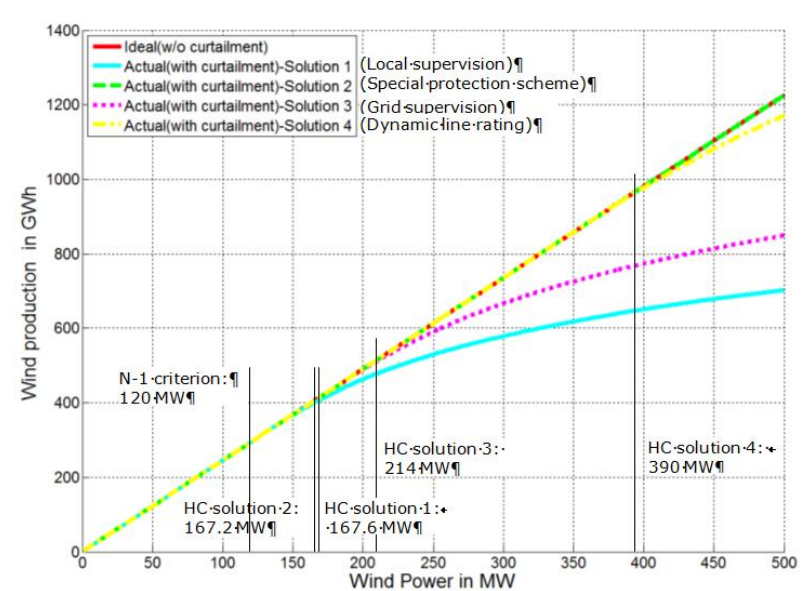

Fig. 8. Annual produced energy as a function of the installed capacity.

\section{Dynamic line rating}

The use ofDLR (solution 4) will greatly reduce the amount of energy that needs to be curtailed. Only for installed capacity above $400 \mathrm{MW}$ does the curtailed energy become visible in Fig. 8.

\section{DISCUSSION}

For classical solutions to reinforce the electrical network to be able to host more wind power, a higher resulting value of the hosting capacity is generally associated with a higher risk of overloading in the network. These risks are carried by the network operator and the network users. Using more accurate models of production and consumption allows for a higher value of the hosting capacity without increasing the risk of overloading. It is therefore recommended to gather, at least hourly, data on variations in active and reactive power at all relevant locations in the grid.

Using curtailment schemes or special protection systems allows for a large increase in hosting capacity without an increase in risk of overloading, as has been shown in this paper. Instead the risk is carried by the wind-park owner through loss-of-production during periods with (otherwise) increased risk of overload.

In the base case, with a meshed operated grid without applying the studied solutions the hosting capacity is a static limit that cannot be exceeded. The resulting threshold effect is known as a possible barrier against wind power. With curtailment schemes, the hosting capacity is no longer a hard limit and the threshold effect disappears.

The use of special protection systems allows for the full capacity of the network to be used without an increased risk of overloading of the network. For the network under study, the hosting capacity is increased by 50 to $100 \mathrm{MW}$, depending on the location. The resulting economic risk for the wind-park owner is small and much less than the costs of building a new transmission line.

Using local supervision only variations in local consumption are compensated; using global supervision also variations at other busses are compensated. Using such schemes, the intermittency of production and consumption no longer limits the hosting capacity. Instead a trade-off can be made between the economic losses due to curtailment and the costs of investing in additional subtransmission lines.

Dynamic line rating has the ability to increase the hosting capacity, even without curtailment or special protection system. However the combination of the three allows for much larger amounts of wind power to be connected without large economic risks associated with curtailment. The largest increase in delivered energy is obtained when the conductor temperature along the line can be accurately estimated. If this is not the case, safety margins are needed that will increase the amount of curtailed energy.

Failure of the curtailment scheme or special protection scheme could result in a large-scale interruption of the supply. Mechanisms are needed to avoid this, e.g. through the introduction of "fail- safe" mechanisms that prevent blackouts due to failures of the smart grid solutions.

\section{CONCLUSIONS}

The studies presented in this paper show that alternatives to the N-1 criterion are possible. Such alternatives allow for much more wind power to be connected without endangering the reliability of supply for other network users. Instead the risk is transferred, as an economic risk, to the wind-park owners.

Further studies needed include additional quantifications of the gain and risk associated with such schemes, for the network operator and for the different network users, including the wind-park owners. The studies should also be extended to include other sources of production (like solar power) and growth in consumption.

Further studies are also needed on the implementation of the various solutions discussed here, including detailed protection, control and communication rules to guarantee a maintained high reliability of the supply for all network users. Pilot installations will be required to evaluate the real-time and practical aspects of the schemes before wide-scale adoption.

\section{ACKNOWLEDGEMENTS}

This work was funded by Elforsk $\mathrm{AB}$ as part of the smart grids programs. Special thanks go to Prof. Per Norberg for his constructive comments on the preliminary results.

\section{REFERENCES}

[1] M.H.J. Bollen, Adapting the Power System to New Challenges, Piscataway, USA: Morgan and Claypool, 2011.

[2] N. Etherden, Increasing the Hosting Capacity of Distributed Energy Resources Using Storage and Communication, Luleå, Sweden: Licentiate thesis, Luleå University of Technology, 2012.

[3] Yu Chen, Math Bollen, Nicholas Etherden, Risk Analysis of Smart Solutions to Increase Wind Power Hosting Capacity in Subtransmission Network, Elforsk report, 2013. http://www.elforsk.se. 